Fecha de recepción: abril 2020

Fecha de aceptación: mayo 2020

Versión final: junio 2020

\section{Las proyecciones públicas de Krzysztof Wodiczko: arte público, monumento $y$ victimización}

Edén Bastida Kullick ${ }^{(1)}$

\begin{abstract}
Resumen: En los últimos años las revueltas sociales en Latinoamerica han estado acompañadas por una nueva forma de interveción estético-política. Lo que podríamos denominar intervenciones audiovisuales en espacio público.

Con la intención de empezar a trazar un recorrido histórico por diversas experiencias que han utilizado la intervención audiovisual como herramienta de ataque simbólico en diversa arquitectura hegemónica. En este texto analizaremos la experiencia del artista polaco Krzysztof Wodiczko, quien con sus proyecciones públicas constituye uno de los referentes principales de este nuevo lenguaje lúminico-proyectivo.

Este trabajo indaga de manera somera en sus postulados estéticos al momento de realizar sus proyecciones públicas sobre diversa arquitectura y monumentos públicos y corporativos, así como su interés primario de desmarcarse de la noción de arte público y el intento de cuestionar en cada una de sus acciones la noción de público y privado.

Igualmente profundizamos en el paso que el artista polaco ha tenido por Latinoamerica en los ultimos años y como podríamos pensar esto como un germen de las acciones proyectivas desobedientes que ahora iluminan nuestros territorios.
\end{abstract}

Palabras clave: Intervención Audiovisual - Proyección Pública - Krzysztof Wodiczko Arte Público.

[Resúmenes en inglés y portugués en las páginas 243-244]

(1) Artista e investigador. Doctor en Teoría e Historia de las Artes por la Universidad de Buenos Aires (UBA). Trabaja los cruces del arte y la política, el audiovisual en múltiples formatos, las intervenciones en espacio público y la imprenta tipográfica.

\title{
Introducción
}

Un referente clave a la hora de pensar las proyecciones en espacio público, sino el más importante a nivel global, es Krzysztof Wodiczko.

Nacido en el año 1943 en Varsovia, Polonia, migra inicialmente a Canadá cargando treinta y cuatro primaveras a sus espaldas y posteriormente se radica en los Estados Unidos. Vive 
en diversas ciudades hasta que mediados de los años noventa se instala en Cambridge, Massachusetts, en donde actualmente reside y donde se desempeña como docente-investigador coordinando el Centro de Estudios Visuales Avanzados, como director del Grupo de Diseño Interrogativo del Instituto Tecnológico de Massachusetts (MIT) y, desde 2010, como coordinador el área de Arte, Diseño y Dominio Público de la Escuela de Graduados en Diseño de la Universidad de Harvard.

La línea de trabajo de Wodiczko es inmensa y variada, pero casi en su totalidad y de manera continua ha estado presente de algún modo lo concerniente al arte público. Al indagar en su obra, se encuentra un rastro de su formación como diseñador industrial en su Polonia natal, ya que conceptualiza, diseña y fabrica objetos móviles en apariencia de corte futurista, como el Homless Vehicle y el Poliscar, desarrollados durante la época que residió en la ciudad de Nueva York. El Homeless Vehicle, diseñado a raíz de la creciente ola de gente sin hogar que azotaba la ciudad en los años ochenta, consistía en un hogar móvil que permitía a las personas sin hogar habitar dicho vehículo de manera momentánea, contando con un lugar donde dormir y guardar sus pertenencias. El Poliscar consistía en un vehículo de comunicación y vigilancia equipado con un monitor de televisión que transmitía programas pregrabados. Estos dos ejemplos móviles se podrían considerar como parte de lo que William Mitchell (1992) llama Arte Público Crítico.

Pero haciendo foco en las intervenciones audiovisuales, me interesa retomar una serie de piezas que Wodiczko nombra Proyecciones Públicas, y que desarrolla desde los años ochenta hasta la actualidad. Estas piezas son acciones proyectivas sobre edificios públicos, monumentos y arquitectura urbana en las que la unión de imagen y receptáculo -en este caso la superficie arquitectónica- contienen y posibilitan una multiplicidad de significantes y, en algunos casos, un choque dialéctico conceptual con el fin de ejercer un proceso reflexivo.

Estas proyecciones públicas en todos los casos vienen a constituir un ejemplo de intermedios en términos de Dick Higgins, ya que amalgaman conceptos y propuestas de la arquitectura, la fotografía, el cine, el video y la performance con el objetivo de resignificar el espacio urbano, más particularmente los monumentos y/o la arquitectura con carga histórica, a los que interviene buscando propiciar un diálogo ciudadano que active la reflexión pública.

\section{Desmarcándose del arte público}

Si uno examina el discurso de Wodiczko así como los análisis de su obra, el artista polaco intenta desmarcarse del lugar de ejemplo vivo del arte público monumental en el que se ve continuamente encasillado, principalmente por no concordar con dos características o conceptos ligados al arte público: su esteticismo burocratizante y una ambicionada pero nunca alcanzada idea de contracultura.

Por un lado, este esteticismo burocratizante refiere a una especie de exhibicionismo gubernamental que se presenta como pro arte y lo utiliza en las ciudades como medio para sus intereses y fines políticos. Estas manifestaciones sólo tienen efectos decorativos y dejan 
a un lado cualquier crítica de los procesos o símbolos urbanos. Igualmente hace énfasis en el grave error por parte de los artistas públicos -error filosófico y político- de creer que la ciudad realmente pueda ser afectada por los eventos de arte público o por las performances y happenings que tienen lugar dentro de los grandes festivales que se realizan en todas las grandes ciudades y en las no tan grandes también. En todos estos casos su operación es simple: decorar la ciudad, apelando supuestamente a una creatividad artística que es siempre funcional a los procesos de configuración social y urbana de lo estatal y corporativo. Por otro lado, vincula al arte público con cierto posicionamiento contracultural snob, que nada tiene que ver con esa contracultura que se respiraba en los años sesenta y setenta a nivel global. Lo snob para el polaco carece de profundidad reflexiva y no se cuestiona la cimentación de los sistemas o aparatos que se combaten. Pone el ejemplo de los artistas oficiales de grafitti quienes, según él, creen que operan de forma contracultural en espacio público dejando marcas inamovibles sobre los muros cuando en realidad siguen ligados al fervor posmoderno de situar el arte oficial en las calles, con el deseo de hacer de la ciudad un inmenso museo o una gran galería manteniendo un supuesto carácter trascendental o supremo de la obra de arte. Si bien Wodiczko se refiere al contexto anglosajón, nuestras ciudades latinoamericanas no están tan lejos de esas operatorias.

Es a partir de estas observaciones y críticas que Wodiczko suscribe al pensamiento desarrollado por artistas y teóricos estadounidenses vinculado a la noción de Arte Público Crítico. En pocas palabras esta noción y las prácticas que involucra se aleja de la auto-exhibición, de la colaboración pasiva en proyectos estatales y de la idea de instaurar grandes galerías en espacios urbanos bajo el impulso de una farsa ideológica de inclusión. El Arte Publico Critico más bien consiste en un juego estratégico a través de interrupciones, infiltraciones y apropiaciones estético-políticas que lleven a cuestionar las operaciones simbólicas, políticas y económicas de la ciudad. Estas estrategias de negociación con el espacio y sus entes rectores son las que constituyen el objetivo de las indagaciones y experimentaciones socio-estéticas en el espacio público de Wodiczko. Para este artista:

El arte hoy en día es una pieza vocal de puzzle complejo que es el discurso del poder y de la libertad que se despliega en espacio urbano. El silencio significaría la aceptación de la desaparición del espacio público, y por lo tanto de la democracia, y el espacio estaría reservado para el uso exclusivo de los detentadores del poder y de los propietarios. Sería una obra de arte total, creada por los poderosos señores de las inmobiliarias y por una nobleza urbana de políticos agusanados (1995, p. 304).

Las proyecciones públicas se distancian de la idea de contracultura snob que describe: de las marcas inamovibles o indesmontables de los grafiteros o de su relación directa con la materia y la superficie. Más bien propone lo contrario, derretir la arquitectura abriendo la posibilidad de un reciclamiento de visiones que se vuelve posible cuando no se dejan huellas materiales. Más que la alteración de los materiales del edificio o monumento, las acciones de Wodiczko vendrían a ser una especie de alteración de la imagen primaria o una cita temporal reveladora de mitos que subyacen en la construcción y la materia. $\mathrm{Al}$ respecto el polaco afirma: 
Quizá se tenga la impresión de que estoy en contra de fenómenos como el del grafiti, pero de hecho estoy totalmente de acuerdo si todos ellos ocurren al mismo tiempo. La ciudad, el dominio público, se volverían un lugar verdaderamente interesante. Un lugar donde podríamos criticar y no permanecer únicamente pasivos o como colonialistas (1995, p. 273).

Las proyecciones públicas sobre superficies de edificios y/o monumentos de Wodiczko intentan cortar el proceso de anestesiamiento de la memoria que subyace a dichas arquitecturas. Buscan develar el mito que se construye y se sostiene en ciertos edificios, quieren hacerlo explícito, desenmascararlo. La visualización pública del mito permite un reconocimiento físico, mantiene ese mito a la vista de todos los transeúntes interpelándolos, incitando la asociación y la reflexión. En palabras de Wodiczko esto se logra con un edificio o monumento al "pellizcarlo, perturbarlo, despertarlo e insertando la voz, experiencias y presencia de esos otros que han sido silenciados, alienados y marginalizados" (1999, n/a). Mediante estas operaciones el edificio ha sido desenmascarado por los espectadores. No hay oposición a quitarle la máscara tal como sucede en la lucha libre mexicana. Wodiczko da las herramientas, para que por medio de una huracarrana ${ }^{1}$ se venza al edificio en el tercer round, este sea derrotado en la pelea y le toque quitarse y perder la máscara.

En otros casos los edificios y monumentos tienen una invisibilidad histórica por lo que estas acciones buscan visibilizarlos resaltando su historicidad mediante intervenciones audiovisuales. La proyección audiovisual constituye una forma eficaz para densificar la relación de ambos, un acercamiento que subraya la relación proyectándola sobre la solidez de la obra arquitectónica.

A través de las proyecciones se logra provocar una interrupción-intrusión. Existe una interrupción del discurso oficial de la arquitectura que hace hablar a lo silenciado del monumento "procurando descubrir no sólo el "original" sino lo que es más importante las "armas" del original". Y en lo que respecta a la intrusión, esta vendría siendo una especie de ataque simbólico, "a medida que la gente se convierte en "intrusa" en los espacios públicos, una pequeña parte de la administración burocrática - un poder ciertamente- de dichos espacios es desgajada" (Mora, 2003, p. 1). Una intrusión simbólica por medio de la cual personas pueden acceder a espacios en los que habitualmente no son aceptados o de los que son directamente expulsados. Sobre lo anterior pienso automáticamente en las tropas zapatistas entrando al Sanborns de los azulejos, en el centro histórico de la ciudad de México a fines de 1914, o la comandanta Esther del EZLN dando un discurso en el Congreso de la Unión aquel marzo de 2001.

Algo importante para agregar es que al momento de la proyección no existe para el espectador diferencia entre la imagen proyectada y el edificio o monumento: es él quien decide si quiere hacer de la imagen generada una contra-imagen o un contra-monumento. Lo que se logra en ambos casos es resignificar, rediseñar, desdibujar y hasta metaforizar la arquitectura mientras dura el haz de luz. A esto Mora lo llama contraarquitectura, debido al interés marcado por destacar las contradicciones en el discurso ligado a la piedra ya que como él mismo afirma: "la arquitectura no solo representa un modelo sino que lo crea con mayor eficacia: no solo es símbolo del orden social y la estabilidad sino que lo impone en gran medida" (Mora 2003, p. 11). 
En las proyecciones públicas que realiza Wodiczko existe un cuestionamiento a las nociones de lo público y lo privado tanto del espacio público como de los edificios y monumentos que interviene. Mediante un hecho proyectivo en el que la imagen se inserta en los edificios y monumentos, reflexiona acerca la función y propiedad de los mismos y revela una zona liminal de aquellos que en apariencia se declaran públicos pero que funcionan con lógicas de espacios de propiedad privada. Son sus "propietarios" deciden quién puede o no acceder a ellos, se encuentran continuamente vigilados por policías o militares y a esto se suman las cada vez más estrictas ordenanzas respecto de la circulación y uso del espacio público que tienen las ciudades. Claramente este arte público crítico, comprometido con la sociedad, más allá de abordar conflictos sociales y políticos, rechaza la idea de un esfera pública pacífica e inmóvil. Al respecto Wodiczko dice: "La paz no es un concepto pacífico. Sólo lo es en el contexto autoritario, pero en la democracia la paz implica tensión y una contradicción dinámica" y para lograr esa tensión o discusión respecto del espacio público el objetivo "no consiste en dañarlo o destruirlo, sino de enrolarlo en nuestro discurso crítico” (1995, p. 248).

Se debe atacar simbólicamente mediante flujo audiovisual, frontal y nocturno, cobijados por la noche, no sólo en función de cuestiones técnicas y lumínicas en pro de la proyección sino también desde el concepto de la dimensión nocturna urbana: es en la noche cuando esos edificios atacados están durmiendo y descansando de sus funciones diurnas, es ahí, en el cuerpo ensoñando, donde será más fácil insertar imágenes y discurso, es ahí, a la sombra de la noche, donde sucede la transmutación y donde los espectadores convocados y los transeúntes que se topan con estas proyecciones -tanto en su noción de individuos como en un proceso de colectivización- logran transformar los espacios públicos en espacios de diálogo, convirtiendo a la vieja usanza las plazas en ágora, en lugares en los que realmente se rompe el ritual de expectación típicamente cinematográfico.

Los comentarios sueltos, los aplausos, las puteadas de algún espectador y la misma presencia de Wodiczko en muchos de los casos ayudan a conformar un espacio de comunalidad estético-dialógico y hasta en algunos casos un amplio ritual colectivo.

Seguramente la recepción ciudadana a través de los años y en los diversos contextos en que ha operado Wodiczko ha variado rotundamente: desde que proyectaba fotografías monumentales sobre grandes edificios en los incipientes años ochenta cuando la gente no acostumbraba ver este tipo de prácticas, hasta las acciones más recientes en las que proyecta en escala monumental y a veces en tiempo real a individuos dando su testimonio sobre sucesos personales e históricos -en lo que constituye una verdadero acto performático y performativo-.

Inicialmente, teniendo en cuenta las variables a través de la historia y de los contextos, la ciudadanía no sabe si está asistiendo a un cine al aire libre, a un espectáculo de diapositivas, a un show de proyecciones animadas o, ya en años más recientes, a uno de esos sobrepublicitados mapping. Lo que es seguro es que siempre la atención se concentra en la imagen audiovisual, al menos primeramente. Wodiczko hace una observación al respecto, al mencionar que al iniciar las proyecciones los espectadores casi nunca ven las estructuras arquitectónicas como imágenes en sí mismas, las miran como superficies de recepción de la imagen o pantallas de proyección, hecho que responde a la fuerte tradición del espectador cinematográfico pasivo. Pero conforme avanza la proyección -aun tratándose de 


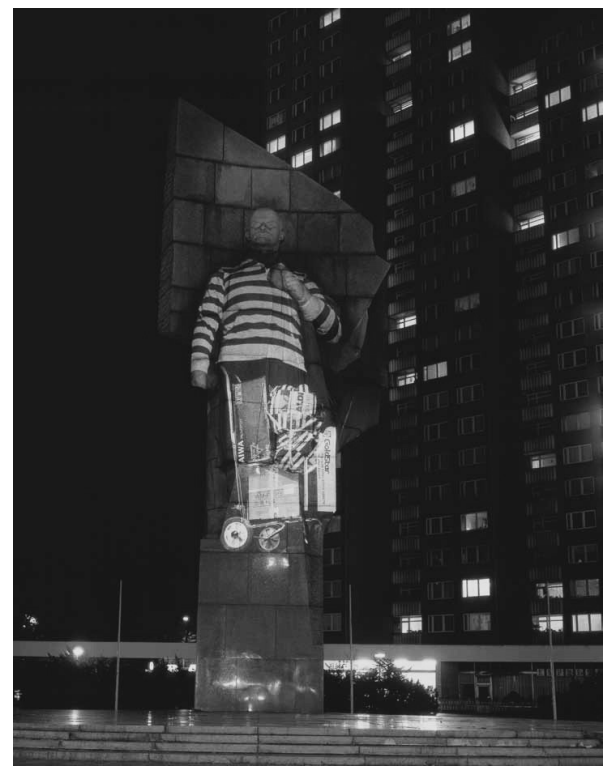

Figura 1. Monumento a Lenin. Berlín, 1990.

imágenes fijas- la mera experiencia de estar situado en ese punto específico de la ciudad observando una alteración arquitectónica, va transformando al espectador en un sujeto activo, y como ya mencioné anteriormente, surgen comentarios al aire: puteadas, citas, recuerdos o risas.

Según Mora, mediante la risa se desmitifica inicialmente la imagen, la cual en muchas de sus proyecciones, tiene fuertes elementos de ironía, para después desmitificar la idolatría burocrática a los monumentos públicos $(2003$, p. 9). Esto nos lleva a pensar en la acción que hizo sobre la estatua de Lenin en Berlín, a pocos meses de ser derrumbado el muro, cuando proyectó imágenes de corporaciones sobre el cuerpo de piedra del camarada en un acto tan crítico como antisolemne. Es interesante ver las afirmaciones de Wodiczko acerca de la risa y su función:

Siempre me regocijo al escuchar las risas de los espectadores. La risa es un buen signo. Nos indica que la seriedad se ha disipado, que tal vez la gente se ha dado cuenta hasta qué punto su vida está condicionada por la arquitectura. Esos monumentos pueden convertirse en una divertida figura de estilo, en una reflexión sobre la experiencia existencial del individuo en el espacio urbano (1995, p. 271).

La acción proyectista no busca únicamente el ataque simbólico que mencionaba anteriormente, busca también constituir espacios de encuentro temporales, generados en un 
entorno preciso aunado a los elementos simbólicos generados por las emanaciones de luz. Sea cual sea el entramado social que logren los espectadores y transeúntes durante la proyección, suele habilitarse un espacio de comunalidad, de diálogo uno a uno, de debate colectivo sea a través de comentarios amenos, discusiones o risas.

\section{Monumento}

En el estudio socio-urbano que realiza Martín Mora sobre las proyecciones públicas de Wodiczko, describe al monumento no sólo como un lugar institucional de discursos de poder, sino más bien, como un modo espacial, metainstitucional de reproducción simbólica, continua y simultánea, tanto del mito general de poder como del apetito individual de dicho poder. El monumento y el edificio tienen vocación de inmovilidad, están arraigados permanentemente al suelo cuajando tiempo y espacio como un hoyo negro de memoria, generando un aura de ritualidad que sostiene un orden de cosas.

Es erróneo pensar necesariamente a los monumentos como entes de la significación colectiva, aun cuando todas las tendencias urbanísticas estatales suponen una obsesión por el patrimonio y en consecuencia, por la conservación de monumentos. Pero estas tendencias realmente no tienen ninguna relación con la memoria urbana colectiva, más bien constituyen un afianzamiento de un sistema global de símbolos y señales urbanas oficiales, ya que el monumento lleva a la exclusión de habitantes constantes de esos espacios, siendo los más evidentes, los vagabundos o sin hogar que se instalan alrededor de estos espacios. Sobre la noción de monumento Wodiczko dice:

Exigiendo nuestra circulación permanente, nuestra percepción vaga, ordenando nuestra mirada, estructurando nuestro inconsciente, encarnando nuestro deseo, enmascarando y mitificando las relaciones de poder, operando con el camuflaje discreto de telón de fondo estético y cultural, el monumento constituye un soporte eficaz y un instrumento ideológico de poder (1995, p. 71).

En una entrevista que le hacen recientemente a Wodiczko durante su visita a Chile en el año 2014, frente a la pregunta acerca de su concepción e idea de funcionalidad del monumento y su relación con la memoria, responde con una reflexión acerca de qué tipo de monumentos se deberían diseñar y, en casos concretos actuales, cuales se deberían alterar o modificar. Para ello la pregunta clave es cómo convertir la conmemoración en práctica para interrumpir la perpetuación del pasado y, consecuentemente, cómo se respeta el dolor y las injusticias sufridos por la gente que ha entregado su vida por diversas luchas -siendo el objetivo de tal práctica la no repetición de ese sufrimiento y atrocidades en el futuro.

Wodiczko parte de la idea de que lo realmente importante de un monumento es su funcionalidad pero - no nos asustemos- habla de funcionalidad no en un sentido urbanístico, de mobiliario urbano, artístico o económico, sino en el sentido de que su función es ser un anclaje al pasado, pulsar un entendimiento para trabajar con miras a una nueva situación. 
Algo así como el $c h^{\prime} a m a n c h t^{\prime} a \tilde{n} a^{2}$, que tiene que ver con el impulso colectivo de realizar un deseo a través de un acto de conocer y actualizar el pasado y de imaginar otro futuro posible (Rivera Cusicanqui 2015, p. 9).

Wodiczko considera que realmente no existen demasiados ejemplos de monumentos que cumplan esta función reflexiva, es por eso que mediante las proyecciones logra realizar alteraciones o modificaciones temporales. Es ahí cuando estos ejercicios de memoria tienden a redefinir la cultura pasada, es decir proporcionar una imagen del pasado con miras hacia el futuro, el Pasado como Futuro.

En muchas de sus proyecciones trabaja con la idea de los humanos como monumentos. Es bajo ese concepto que pone a dialogar a veteranos de guerra, migrantes, inmigrantes y vagabundos con los monumentos -estructuras simbólicas-. Es en estos casos en donde apreciamos que el monumento también puede ser una persona: son monumentos vivientes de su propio y dramático pasado y también de las enseñanzas colectivas. A través de estas acciones busca dar habla a esos monumentos silenciados y olvidados y repentinamente activados mediante testimonios y experiencias. Esta es la utopía que se plantea Wodiczko, lograr que como sociedad realicemos este tipo de monumentos: "Los excluidos, pueden convertirse en esos monumentos que funcionen, monumentos vivos, hablantes y activos. Y su trabajo puede conectarse de alguna forma con los monumentos que queremos construir como instituciones funcionales" (Villarroel, 2014).

Volviendo a las utopías, el arte en ámbito urbano, puntualmente el arte público crítico, es atravesado e impulsado en gran parte por el ideal de trazar una nueva forma de constituir y de organizar las ciudades. Esto constituye un horizonte permanente en ese tipo de prácticas, la búsqueda micro de plantear diversos caminos en que los habitantes de la ciudad se organicen, habiten y se apropien de las metrópolis. Las ideas de Wodiczko comparten esta línea: las experiencias que propone a través de sus objetos, instrumentos, vehículos y proyecciones públicas, son ejemplos concisos de intervenciones urbanas que intentan imaginar y poner en reflexión otro tipo de organización urbana. Pero como en todos los ámbitos sociales sabemos que las utopías están desacreditadas o de capa caída, ya cualquier cambio profundo parece irrealizable, ya nada es creíble. Sobre esta desacreditación de las utopías, Paul Virilio señala que esta se debe principalmente a la aceleración temporal en la que vivimos en las grandes urbes, la cual claramente ha esfumado la potencia creativa de las mismas. Es justamente esta celeridad de los tiempos la que obtura la posibilidad de reflexionar al respecto e impide el imaginar otras formas posibles de habitar y organizar la ciudad. Las ciudades se están transformando en una especie de metaciudades o ciudades virtuales:

La ciudad real, localmente situada y que incluso daba su nombre a la política de las naciones, cede el puesto a la ciudad virtual, esta metaciudad desterritorializada que se convertirá así en la sede de esta metropolítica cuyo carácter totalitario, o mejor globalitario, no pasara inadvertido para nadie (Virilio 1999, p. 20).

Ello sumado a las características de vigilancia y represión que se dan en los espacios públicos que impiden ante todo el diálogo entre los habitantes y, por lo tanto, los procesos 


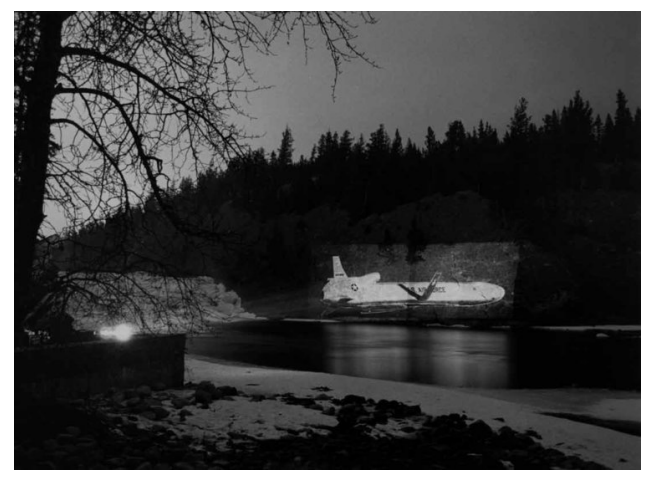

Figura 2. Baow Falls.

de organización social. En México y Argentina ${ }^{3}$ puedo mencionar al respecto las aprobaciones y entradas en vigencia en el caso mexicano de la Ley de Seguridad Nacional, impulsada recientemente por el expresidente Enrique Peña Nieto y, en el argentino, de la Ley Anti-Terrorista, que fue aprobada durante el período kirchnerista y que el gobierno de MMLPQTP -Mauricio Macri- enarboló, convirtiéndola en su principal herramienta y caballito de batalla para dar rienda suelta a prácticas represivas diversas. Es la vuelta a la ciudad cerrada: "ciudades privadas, protegidas por su cerco eléctrico, cámaras de seguridad y guardias (...) son síntomas de la regresión patológica de la ciudad, según la cual la cosmópolis, la ciudad abierta de ayer, cede lugar a esta claustrópolis" (Virilio, 2006, p. 73). Un rasgo que deseo abordar respecto de la manufactura de la proyección y los códigos que despliega Wodiczko, rasgo que considero controversial, es la espectacularidad. En el rastreo que uno hace de sus intervenciones, una característica inamovible a través del tiempo es la presencia de proyecciones en gran formato con fuertes características de espectacularización. Con espectacularización me refiero no sólo a las grandes dimensiones de las proyecciones que trabaja, sino al hecho de realizar una convocatoria directa, con fecha y horario precisos, invitando a un público a ser espectador, ello sumado al cobijo institucional bajo el que se han dado casi todas sus proyecciones. Ante esto, se vuelve interesante preguntarse hasta qué punto se podrá hacer una acción de contenido crítico sobre la arquitectura institucional, teniendo el aval de las dependencias burocráticas.

Curiosamente el primer ejercicio proyectista del polaco se realiza sin convocatoria pública y a su vez es la única ocasión en la que no proyecta sobre edificios o monumentos realizados por el hombre. Esta acción se desarrolló en 1983, en el Parque Nacional Bow Falls de Alberta Canadá, un bosque situado dentro de los Montes Rocallosos cercano al epicentro turístico de Bow Falls. En esta primera ocasión, proyectó con un cañón Pani de fabricación austríaca, una imagen a gran escala de un misil Cruise. La acción sucedía en un momento en el que había protestas a lo largo de todo el territorio canadiense frente a la idea del gobierno de hacer pruebas misilísticas en la provincia de Alberta, ya que el gobierno argumentaba que las características físicas de esta provincia eran similares a las 
de Siberia en donde la Unión Soviética supuestamente había realizado pruebas nucleares y agregaban que hacerlas allí sería un ahorro para el erario público.

Esta primera proyección pone de manifiesto una clara distancia respecto de la espectacularización que es parte constitutiva de su obra posterior. En el caso de Bow Falls, el hecho de proyectar en un entorno natural -situación que no volvió a repetir-apuntaba más a la difusión posterior en los medios y en el mundo del arte que a la gestación de una situación espectacular de expectación.

Luego de la proyección de Bow Falls, su obra comenzó a inclinarse hacia lo espectacular pero siempre con el objetivo claro de invertir el discurso unilateral de los poderes estatales y corporativos para que el espectador reflexione y se sensibilice acerca de las problemáticas sociales propias de cada entorno pero también para que la acción realizada devenga en un evento comunal temporal, en un espacio de debate público sobre los temas tocados por las proyecciones y por el diálogo que generan con edificios y monumentos. Al decir de Di Paola: "Sus proyecciones, que unen al sentido de la imagen mediática contemporánea la imagen del monumento público del pasado, son un aprovechamiento táctico para convertir en espectáculo sus intervenciones en estos espacios públicos y difundir sus mensajes críticos" (2009, p. 134).

\section{Victimizaciones}

$\mathrm{Al}$ analizar la obra proyectista de Wodiczko, un elemento fuerte que aparece como un vil fantasma nocturno sin previo aviso es la utilización de víctimas de diferentes conflictos para enunciar una crítica respecto de acontecimientos históricos y de actualidad. Desde ex veteranos de guerra, migrantes e inmigrantes, vagabundos y sin hogar, hasta familiares de personas violentadas, en todos estos casos la cualidad de víctima está presente y explicitada en el hecho proyectivo. En las primeras experiencias las víctimas se presentaban a través de una imagen y posteriormente, al incursionar en la imagen en movimiento, solían estar presentes en el momento de la proyección, es decir que eran proyectadas en tiempo real mientras verbalizaban su testimonio.

Sin dudas hay quienes consideran que una de las funciones del arte consiste en dar voz a las víctimas. Lo interesante en el caso de diversas obras audiovisuales que trabajan la violencia es el hecho de que en muchas ocasiones no existen cuerpos sino residuos conceptuales de estos: trabajan las condiciones materiales de la violencia pero no la condición de sujeto de sus víctimas. He intentado centrar mi quehacer artístico partiendo de esta última idea, de que no hay víctima y de que existe un victimario que es un sistema, una maquinaria, pero la obra de Wodiczko me lleva a poner en cuestión esa idea: cuando este artista lleva la voz de la víctima a los espacios de poder, a los espacios del victimario, no puedo dejar de valorar la potencia crítica de este encuentro. Pero al mismo tiempo esta potencia se ve limitada por el hecho de que para realizar estas proyecciones públicas es necesario que existan permisos gubernamentales para hacerla: la idea del administrador del espacio del victimario autorizando al artista y a la víctima a utilizar ese espacio me genera una suerte de rechazo que me devuelve a mi idea original de hacer foco en el sistema. 

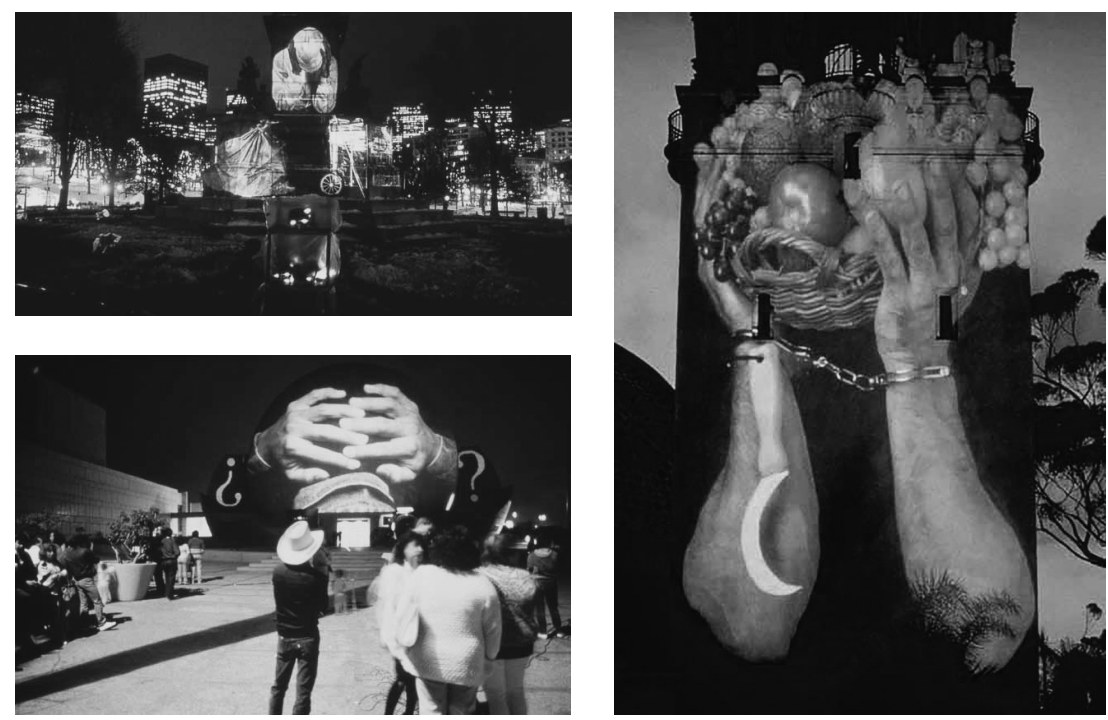

Figura 3 (arriba izq.). Sin hogar II. Memorial de la Guerra Civil, Boston, 1986-1987. Figura 4 (abajo izq.). El Centro Cultural. Tijuana, 1988. Figura 5 (derecha). El Museo de San Diego. San Diego, 1988.

En la primera etapa de Wodiczko -la de la imagen fija- estas acciones podían situarse en un lugar más nebuloso, ya que la víctima sólo hacía un acto de presencia fantasmagórica sobre las membranas arquitectónicas. Como ejemplos de esto podemos mencionar la acción que realizó en el Memorial de los Soldados de la Guerra Civil en Boston Massachusetts en 1987, en la que proyectó imágenes de indigentes cabizbajos cubriéndose del frío con las manos en la cabeza como gesto de desesperación. Esta imagen se complementaba con imágenes de carritos de supermercados como una especie de mobiliario de estos personajes. Un año después proyectó en el Calton Hill de Edimburgo, Escocia, en pleno apogeo del thatcherismo en Gran Bretaña, imágenes de seis tipos de excluidos de la sociedad escocesa sobre seis muros de la edificación. Una embarazada, un inmigrante, un drogadicto, una anciana, un minusválido y un desempleado eran proyectados de forma permanente agregando la frase "Pax Britannia" y "Moriturite Salitant" -los que van a morir te saludan-. Ese mismo año en Tijuana, México proyectó sobre la fachada cilíndrica del Centro Cultural de Tijuana (CECUT), la imagen de la cabeza de un migrante de espaldas justo en el momento que la migra lo detiene, con las manos en la cabeza, acompañado de unos signos de pregunta. Esa potente imagen que había sido ampliamente difundida y vista por los ciudadanos en distintas partes de la ciudad de Tijuana, al ser proyectada funcionó como una especie de ampliación o resignificación de los hechos diarios que suceden de forma masiva y continua en esta frontera. Paralelamente, del otro lado de la frontera, en uno de los muros del Museo de la Jolla en San Diego California, se proyectaban unas 

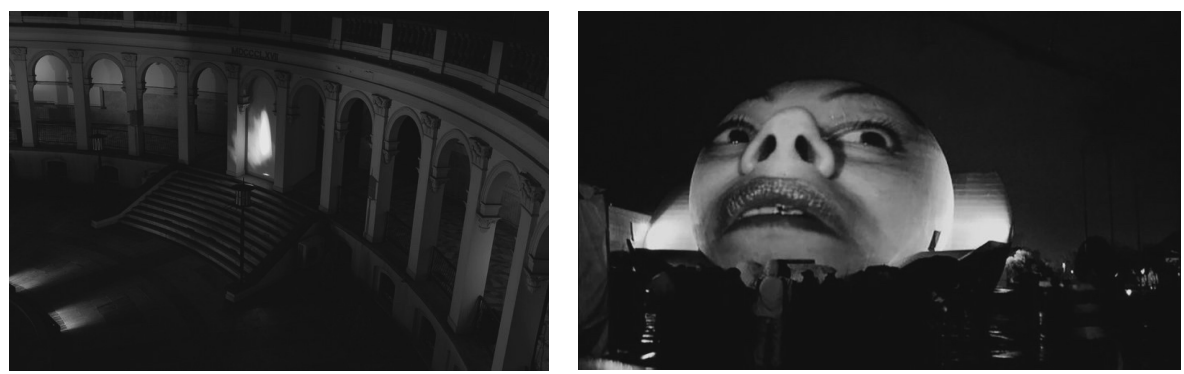

Figura 6 (izquierda). La llama del veterano. Cracovia, 2010. Figura 7 (derecha). La proyección de Tijuana. Tijuana, 2001.

manos sosteniendo un tenedor y un cuchillo, y en otro de sus muros, un par de manos sosteniendo una canasta con frutas, esas que las manos inmigrantes pizcan diariamente, imagen que se transformaba en unas manos esposadas.

Cuando el polaco empieza a utilizar audio e imágenes en movimiento de manera simultánea, esta noción de la victimización se complejiza. Curiosamente, la primera ocasión en que utiliza el soporte del video y el audio amplificado tiene lugar en su país natal Polonia, más específicamente durante un festival en Cracovia. Durante tres noches de los primeros días de octubre de 1996, "Wodiczko les dio voz a los sin voz". No es algo que el artista no haya pensado en sus anteriores intervenciones, es solo que el avance de las nuevas tecnologías le permitió dar lugar y volumen a la voz de los marginados en la vía pública. Los protagonistas de esta proyección fueron los vulnerables sociales pero en este caso, a diferencia de las proyecciones los ochenta, se mostraban imágenes de video de sus manos sosteniendo un cigarrillo, portando una vela o pelando papas con diferentes movimientos y herramientas. Estas imágenes de media hora de duración se proyectaron en la torre del Ayuntamiento de la ciudad, un edificio histórico del siglo XIV, mediante loops permanentes y acompañadas de audios testimoniales de las víctimas en los que narraban su historia personal y las vejaciones que habían sufrido.

Para ampliar la cuestión acerca de la utilización de víctimas en su obra, profundizaremos en estas intervenciones acontecidas en territorio mexicano. Trece años después de su primera intervención en Tijuana, -aquella en la que proyectó la ya nombrada imagen de un migrante con las manos en su nuca al momento de ser detenido por ilegal- regresa a la ciudad cargado de la más novedosa tecnología en proyectores y circuito cerrado para hacer una intervención nuevamente en el CECUT, en el marco del festival inSITE2000. Esta vez traía una nueva línea de trabajo que había empezado a experimentar en 1996 en Cracovia, vinculada al uso de la imagen de video y al trabajo sonoro para amplificar el testimonio de las víctimas.

El artista trabajó con un grupo de mujeres mexicanas ubicadas afueras del centro cultural desde donde narraban en vivo las experiencias traumáticas en las que estuvieron envueltas por su doble condición de subordinación: ser mujer y ser migrante. Las mujeres eran gra- 
badas y proyectadas en tiempo real sobre la fachada circular del edificio, con un particular close-up que generaba una idea de proximidad o intimidad pero también una sensación de exposición de esas mujeres vulneradas. Los testimonios de las mujeres se basaban en problemáticas de acoso sexual en el ámbito laboral, brutalidad policial, violencia doméstica y desintegración familiar.

Me arriesgaría a decir que este tipo de proyecciones públicas en donde existe un testimonio de diversas víctimas podría considerarse una espectacularización de las emociones. Lo interesante es pensar que esos testimonios cargados de fuertes grados de dolor y seguramente silenciados y recluidos por muchísimo tiempo al ámbito de lo personal y/o privado, al hacerse públicos se transmutan hacia una experiencia catártica sanadora. En palabras de Wodiczko: "a veces es más fácil decirle las cosas a una multitud de personas que a alguien en el hogar" (1999, p. n/a).

Pero la cuestión a tratar es si el uso de dispositivos macro que buscan ampliar la dimensión de las proyecciones en los receptáculos no es contradictoria con la cualidad íntima, personal y traumática de los testimonios tocados en las obras, al menos éticamente. Tomo las palabras de Wenger, quien dice que la realización final del proyecto artístico "posibilita la verbalización de aquello que es reprimido, latente, y que es puesto de manifiesto a través de la palabra, a la manera de una cura psicoanalítica" (2015, n/a). Según Freud esta cura se da inicialmente en el momento que el trauma se recuerda para su posterior verbalización, y de esta forma disiparse.

Considero que el hecho de poner a las víctimas en los espacios o símbolos de poder lo que hace es señalizar al sistema que funge como victimario y causante de las problemáticas sociales, los gobiernos y corporaciones. En sus proyecciones, Wodiczko da un tratamiento especial de estas problemáticas: no se limita únicamente a posibles procesos curativos o sanadores desde el arte, sino que también busca desenmascarar al victimario, esa maquinaria atroz y salvaje, mediante una aguda y pertinente ubicación espacial de las víctimas.

\section{La puesta en escena}

Por más que en ningún momento puedo equiparar la obra de Wodiczko a un proceso del quehacer cinematográfico, es interesante indagar en los procesos de registro o puesta en escena previos a la proyección que realiza el artista. Si uno se aproxima a los diferentes materiales visuales que conforman la obra de este artista, encuentra un proceso muy ligado a las cuestiones de preproducción cinematográfica que tiene que ver con el scouting o como le dicen en el mundo del cine, la búsqueda de la locación. Su trabajo previo consiste en realizar recorridos urbanos en busca del lugar ad hoc para intervenir; esto aunado a una investigación profunda en materia histórica de la arquitectura elegida. En el documental Projections (1991) del director canadiense Derek May, vemos al artista recorriendo las ciudades tomando una cantidad infinita de fotografías instantáneas, realizando cartografías, planos y mapas urbanos, con el fin de realizar una elección correcta del lugar a proyectar. En su primera etapa de trabajo, es decir desde los años ochenta hasta mediados de los noventa, opera con imagen fija proyectada en una macro amplitud, trabajando en la ma- 


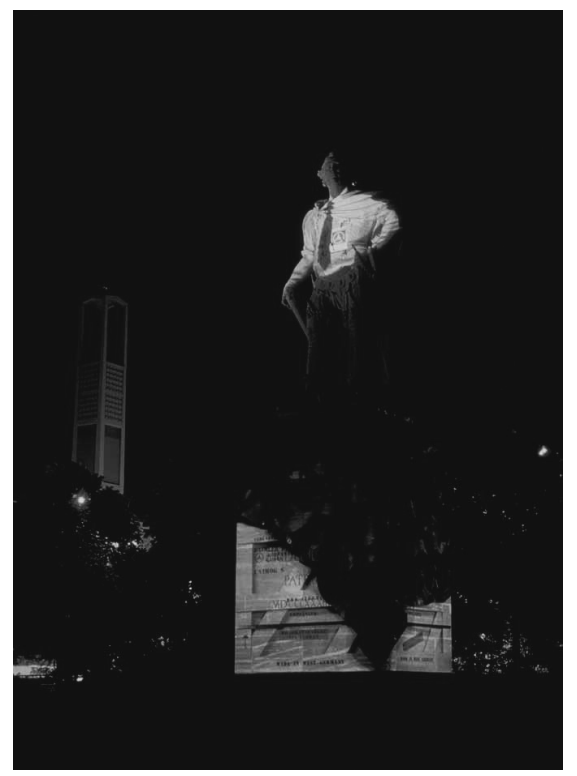

Figura 7. Monumento a

Friederich II. Kassel, 1987.

yoría de los casos con previas puestas en escena fotográficas. Buscaba imágenes precisas que pudieran fusionarse con la arquitectura y por esta razón realizaba sesiones de fotos con diversos personajes que aceptaban posar para este fin. Así obtenía un plano cerrado de un ojo, manos en distintas posiciones, dependiendo el edificio donde se proyecte, manos de esqueleto tocando el acordeón, vagabundos y migrantes en diversas situaciones, hasta lo que podríamos llamar fotografía de producto, como aquellas en que vistió con ropas los monumentos de Federico II de Prusia en 1987 y de Lenin en 1990. Quisiera resaltar la proyección que realizó en 1990 en el museo de Jerusalem, cercano a la plaza Zion de esta ciudad, donde Wodiczko mezcló un registro de puesta en escena ficcional con un típico registro documental. Mediante la ayuda de un modelo, fotografió un brazo sosteniendo un bastón replicando al de Moisés y luego se acercó al aeropuerto de Jerusalem donde estaba llegando gran cantidad de inmigración judía proveniente de la recién extinta Unión Soviética y tomaba fotografías de sus maletas con las etiquetas del viaje que realizaron -Moscú - Tel Aviv-, así de sus pasaportes, los cuales posteriormente serían proyectados sobre la fachada del museo. En este caso, en una especie de torre del museo, se proyectó lo relacionado a las recientes migraciones rusas y en otro muro de similares características la imagen de bastón, activando una puesta en juego de lo histórico y lo actual, de lo ficcional y lo documental.

En toda esta primera etapa de producción, comprendida entre 1983 y 1996, empezó a utilizar el dispositivo de video y sistemas sonoros: la puesta en escena era un elemento 
clave para conseguir imágenes fotográficas pertinentes que pudieran ser proyectadas en muros y monumentos.

Es a partir del uso del dispositivo del video que comienza a variar sus procesos de puesta en escena. A partir de ahora, casi en todos los casos sus realizaciones estarán más ligadas a una forma documental, casi siempre teniendo como metodología la entrevista para que de esta forma los protagonistas cuenten sus testimonios. Estas experiencias se aproximan a una especie de teatro documental en espacio público, magnificado mediante proyecciones. Se vuelve importante mencionar que a partir de la utilización del lenguaje audiovisual propiamente dicho -imagen electrónica más sonido, ya sea grabado previamente a la proyección o filmado en tiempo real para su proyección sincronizada- la línea que ha mantenido Wodiczko se ha centrado en darles visibilidad y voz a las víctimas como él mismo las llama. No encuentro experiencias en su posterior carrera que se despeguen de esta línea iniciada aquel 2 de Octubre de 1996 en Cracovia cuando empezó a utilizar video en sus proyecciones.

\section{Su paso por Latinoamérica}

Haré una breve profundización sobre la presencia que Krzysztof Wodiczko ha tenido en el contexto latinoamericano, abordando en principio dos intervenciones ya nombradas anteriormente, realizadas ambas en la ciudad de Tijuana, México, con proyecciones simultáneas del otro lado de la frontera en San Diego California. El detalle de estas piezas ayudará a entender gran parte de su obra, ya que considero son ejemplos emblemáticos de su producción y constituyen reflexiones propias de la época y de las formas en las que trabajaba en cada caso.

La primera experiencia realizada en el año 1988 consistió en una proyección de forma esférica realizada sobre la fachada del CECUT -conocido como La Bola- que fue construido por Pedro Ramírez Vázquez y Manuel Rossen Morrison y tenía como propósito presentar el arte mexicano ante la comunidad local, nacional e internacional. Este espacio se construyó dentro de un plan gubernamental cuyo objeto era potencializar la escena artística de Tijuana y a su vez promover un turismo cultural. Esta proyección era parte de una exposición individual que el polaco estaba realizando en el Museo de Arte Contemporáneo de la Jolla en San Diego, California, en relación a los procesos migratorios. Como bien sabemos, Tijuana es una de las fronteras más complejas del mundo, principalmente por los procesos de control migratorio y la militarización que emplea el gobierno estadounidense.

Estas dos proyecciones paralelas dialogan tanto temporal como conceptualmente de cada lado de la frontera y es interesante el punto de vista de la imagen proyectada en Tijuana -un migrante siendo detenido de espaldas- que claramente remite a la detención durante el trayecto rumbo al "American Dream": ¿ cuántas veces los habitantes tijuanenses no habrán visto esta imagen de forma tangible? A su vez, en San Diego las imágenes disparaban un sinnúmero de reflexiones - un tenedor y un cuchillo, una canasta con frutas, y luego unas manos esposadas-. Es interesante el comentario que hace una güerita gringa en el documental Projections (1991) quien dice: "veo una sirvienta sosteniendo frutas. No me 
gustan los sirvientes". ¿A que se referirá esa niñita gringa, futura militante de agrupaciones de supremacía blanca en el gabacho o prominente abogada defendiendo inmigrantes? ¿A que no le gustan porque los detesta o a que no le gusta que exista la servidumbre como forma de relación social?

Wodizcko volvió a realizar una proyección pública en Tijuana que denominó La Proyección de Tijuana (2001), en el marco de inSITE 2000, festival organizado por una empresa binacional estadounidense-mexicana de carácter no lucrativo de arte contemporáneo.

Más allá de estas dos proyecciones que realizó en Tijuana, primero en 1988 y posteriormente en el 2002, en los años recientes Krzysztof ha tenido acercamientos a realidades latinoamericanas, pero no precisamente realizando proyecciones públicas: más bien ha estado en nuestros países dictando charlas y talleres y transmitiendo su obra y experiencia mediante otros formatos.

Después de aquella experiencia del año 2002 dentro de la exposición inSITE2000 en Tijuana, tuvieron que pasar otros trece años para que el polaco volviera a realizar alguna actividad en algún país latinoamericano. Fue para ser exactos un 17 de Junio del 2014, fecha en que realizó la charla pública Design for Civic Engagement: Instruments of Expression, Dialogue and Collective Critique impartida en la Universidad Adolfo Ibáñez de la ciudad de Santiago de Chile. La presente charla era un trabajo colaborativo entre esta universidad chilena y la coordinación del área de Arte, Diseño y Dominio Público de la Escuela de Graduados en Diseño de la Universidad de Harvard, institución de la cual Wodiczko es parte. Esta charla tuvo como objetivo principalmente poner en diálogo a Krzysztof Wodiczko con el artista turco Orkan Telhan, con estudiantes, militantes de movimientos sociales, representantes institucionales y artistas, para en conjunto reflexionar cómo de a poco y desde el punto de vista de los actores locales se ha empezado a instalar lo que ellos llaman un cambio cultural en la sociedad chilena, después de muchos años de traumas post-dictadura. En este encuentro la voz se centró, principalmente, en representantes de los movimientos estudiantiles que desde 2006 enarbolaron la emblemática "Revolución Pingüina", cuestionando el sistema educativo legado de la dictadura pinochetista y llevando adelante las masivas movilizaciones de 2011 en las que todos los movimientos estudiantiles del país con sus diferentes Federaciones salieron a la calle masivamente intentando entablar un diálogo con el gobierno nacional respecto a la educación pública del país. Fue un diálogo abierto y estructurado donde Wodiczko y Orkan se iban empapando de la realidad chilena, de su pasado breve por el socialismo, su dictadura atroz y sus luchas recientes. El polaco y el turco se limitaron a exponer sus ideas respecto a nociones del espacio público, su dicotomía en realidades netamente neoliberales como las de donde ellos habitan y la chilena. Fue un diálogo productivo que contó con la participación de referentes del movimiento estudianti, por más que se llevó a cabo en una universidad privada.

En su estancia en Santiago y a la par de la charla pública que se llevó a cabo en la Universidad Adolfo Ibáñez, Wodiczko brindó un taller sobre proyecciones públicas dirigido a diferentes referentes del movimiento estudiantil así como a artistas. Lo interesante en este caso es que, a diferencia de las magnas proyecciones en espacio público que conforman en gran medida su obra, en este caso la propuesta consistía en hacer recorridos urbanos con proyectores de pequeño formato teniendo como idea común la experimentación desde lo particular a lo colectivo. 
La noche estaba preparada para las acciones. Una crónica encontrada de este taller menciona que como es costumbre la neblina abrazaba la noche santiaguina y qué mejor atmósfera para realizar proyecciones en las calles. Partiendo de la Plaza Italia, hicieron un recorrido por las calles del centro de Santiago proyectando sobre diversos edificios y monumentos, experimentando con proyecciones sobre cuerpos y pancartas, siempre vigilados por los sorprendidos carabineros que no sabían lo que sucedía y quienes -imagino, no puedo asegurarlo- en algún momento se acercaron a preguntar qué pasaba y ante la presentación del permiso otorgado a la Universidad Adolfo Ibáñez todo siguió su cauce. La última experiencia en territorio latinoamericano que ha realizado Wodiczko fue en la exposición Pseudomatismos que realizó el artista mexico-canadiense Rafael Lozano Hemmer en el Museo Universitario de Arte Contemporáneo (MUAC) de la ciudad de México de octubre de 2015 a abril de 2016. En esta exposición, Wodiczko acompañó como colaborador a su colega y amigo Rafael dentro del Pabellón de Ampliaciones, con la pieza Zoom Pavillon que consistía en una instalación interactiva de algoritmos de reconocimiento facial. La instalación funcionaba como un ejercicio de reflexión en cuanto a los procesos de vigilancia urbana, tanto en la calle como respecto de las relaciones de los individuos con entidades burocráticas. En este caso, la pieza que estaba acompañando no se realizaba en espacios urbanos, ni sobre edificios y monumentos, sino que se llevaba a cabo en una sala del museo y se activaba al entrar espectadores a la sala. Al ingresar una persona, automáticamente doce cámaras industriales la registraban haciendo hincapié en su rostro, haciendo zoom para su proyección en tamaño arquitectónico mediante dos grandes proyectores. Un ejercicio de utilización de proyecciones basado en la expansión de los rostros de los asistentes, buscando conexiones o relaciones entre el público y poniendo en la mesa los cuestionamientos básicos de la video-vigilancia.

Dentro de la misma exposición, se instaló una pequeña sala que mostraba un recorrido breve a manera de video-instalación con el registro de las diferentes intervenciones que el polaco ha realizado alrededor del mundo. El registro ponía foco en los artefactos y aditamentos tecnológicos utilizados a la hora de realizar las magno-proyecciones.

$\mathrm{Al}$ igual que en su estancia en Chile, durante su paso por la Ciudad de México no realizó ninguna proyección pública, limitando su presencia a una charla que brindó en el MUAC. Capaz no fue necesario que se realizara una proyección del polaco en nuestros contextos, nos la imaginaremos y la realizaremos en un futuro cercano y de otras formas más austeras. Más bien ya lo estamos haciendo.

La cantidad de nomenclatura que se ha utilizado para las intervenciones audiovisuales del polaco es inmensa. A sus piezas se las ha llamado: proyecciones públicas, intervenciones audiovisuales, exposiciones temporales, exposiciones permanentes, video-esculturas-monumentales, murales oficiales, grafiti no oficial, espectáculos monumentales oficiales, festivales urbano nocturno, teatro épico arquitectónico etcétera, etcétera, etcétera, pero independientemente del término, de lo que se trata es de proyectar una imagen sobre el edificio que corresponda con la vida, con la realidad. Ya sean manos gesticulantes, rostros, cuerpos, velas, misiles, cadenas, todas estas imágenes dan testimonio del pasado y del presente, hacen memoria, invitan a la reflexión. Y en todos los casos, el transeúnte y el espectador se ven interpelados y convocados a un proceso de observación, de pensamiento en el que mediante formas narrativas experimentales se logra generar un distanciamiento crítico. 


\section{Notas}

1. Movimiento de la lucha libre creado por el "Huracán Ramírez" que consiste en someter al contrincante, partiendo desde una posición inicial sentado de frente en los hombros del mismo. El ejecutor desdobla su cuerpo hacia atrás pasando por entre las piernas del adversario, de tal forma que el peso y la presión de piernas aplicadas al cuello del rival. Terminando en una posición de espaldas planas, y sometido de brazos y piernas. Una llave contundente que en casi todas las ocasiones vence al rival.

2. Concepto aymara que describe el impulso colectivo de realizar un deseo. Es el acto de conocer/actualizar el pasado y de imaginar otro futuro posible en el pasado.

3. Países en los cuáles radico.

\section{Bibliografía}

Auge, M. (1993). Los no lugares, Espacios de anonimato: Una antropología de la sobre modernidad. Barcelona: Gedisa.

Bhabha, H. K. (2002). El lugar de la cultura. Buenos Aires: Manantial.

Berardi, F. (Bifo) (2007). Generación Post-Alfa: Patologías e imaginarios en el semiocapitalismo. 1a. edición, Buenos Aires: Tinta Limón.

Blanco, P. (2001). Modos de hacer: arte crítico, esfera pública y acción directa. Salamanca: Universidad de Salamanca.

Bourriaud, N. (2009). Postproducción. 3a. edición, Buenos Aires: Adriana Hidalgo editora. . (2015). Estética Relacional. 3a. edición, Buenos Aires: Adriana Hidalgo editora.

De Certau, M. (1991). La invención de lo cotidiano: Artes del hacer. México: Universidad Iberoamericana.

Di Paola, M. (2009). “Krzysztof Wodiczko; proyecciones”. En AA.VV. La memoria del otro. Bogotá: Museo de arte de la Universidad Nacional de Colombia. Consultado el 6 de agosto de 2018.

Duque, F. (2002). Arte Publico y Espacio Político. Madrid: Akal.

Foster, H. (1986). Recodings, Art, Spectacle and Culture Politics. Seattle: Bay Press.

Groys, B. (2014). Volverse Público: Las transformaciones del arte en el ágora contemporánea. 1a edición. Buenos Aires: Caja Negra.

Guattari, F. y Rolnik, S. (2013). Micropolítica: Cartografías del deseo. 2a edición, Buenos Aires: Tinta Limón.

Kozak, C. (Ed.) (2015). Tecnopoéticas Argentinas: Archivo blando de arte y tecnología. 2a edición, Buenos Aires: Caja Negra.

Machado, A. (2015). Pre-Cine y Post-Cine: En diálogo con los nuevos medios digitales. 1a edición, Buenos Aires: La marca editora.

Manovich, L. (2008). Lenguaje de los nuevos medios de comunicación. Buenos Aires: Paidos.

Mitchell, W.J.T. (1992). Introduction: Utopia and Critique, Art and the Public Sphere. Chicago: The University of Chicago Press. 
Mora Martinez, M. (2003). “Tomar por asalto el espacio urbano: El Arte Público Crítico de Krzysztof Wodiczko”. En Regalado Santillán-Rámirez Saiz (Coord.), Intervención ciudadana e innovaciones politicas. Guadalajara: Editorial de la Universidad de Guadalajara.

Olea, O. (1980). El Arte Urbano. México: Universidad Nacional Autónoma de México.

Rivera Cusicanqui, S. (2015). Sociología de la imagen. la edición, Buenos Aires: Tinta Limón.

Serra, C. (2001). "Krzysztof Wodiczko". El País, 13 de julio de 2001. Consultado el 15 de septiembre de 2013.

Villarroel, F. (2014). "Forma de ser Visible". Entrevista realizada a Krzysztof Wodiczko, Santiago de Chile, 23 de julio de 2014. Consultada el 10 de noviembre de 2018.

Virilio, P. (1999). “Télésurveillance global”, Le Monde diplomatique, no.545, Paris.

. (2006). Ciudad Pánico. El afuera comienza aquí. Buenos Aires: Libros del Zorzal.

Wenger, R. (2015). "K Wodiczko y la resignificación crítica de la memoria urbana". (Sin Referencia). Consultado el 10 de mayo de 2014.

Wodiczko, K. (1995). Art public, art critique. Textes, propos et documents, Ėcole Normale de Beaux-Arts. Paris: Col. Ėcrits d'artistes.

. (1999). Critical Vehicles: writings, projects, interviews. Boston: MIT Massachusetts Institute of Technology.

. (2012). Cine Expandido. 1a edición, Saenz Peña: Universidad Nacional Tres

de Febrero.

\section{Filmografía}

May, D. (1991). Projections. Canada: National Film Board.

\section{Imágenes:}

Monumento a Lenin. Berlín, 1990.

Sin hogar II. Memorial de la Guerra Civil, Boston, 1986-1987.

El Centro Cultural. Tijuana, 1988.

El Museo de San Diego. San Diego, 1988.

La llama del veterano. Cracovia, 2010.

La proyección de Tijuana. Tijuana, 2001.

Monumento a Friederich II. Kassel, 1987.

Abstract: In recent years, social revolts in Latin America have been accompanied by a new form of aesthetic-political intervention. What we could call audiovisual interventions in public space.

With the intention of beginning to trace a historical journey through various experiences that have used audiovisual intervention as a symbolic attack tool in various hegemonic 
architectures. In this text we will analyze the experience of the Polish artist Krzysztof Wodiczko, who, with his public projections, constitutes one of the main references of this new lumen-projective language.

This work explores in a superficial way its aesthetic postulates when making its public projections on various architectures and public and corporate monuments, as well as its primary interest in distancing itself from the notion of public art and the attempt to question in each of its actions the notion of public and private.

We also delve into the step that the Polish artist has taken for Latin America in recent years and how we could think of this as a seed of the disobedient projective actions that now illuminate our territories

Keywords: Audiovisual Intervention - Public Projection - Krzysztof Wodiczko - Public Art.

Resumo: Nos últimos anos, as revoltas sociais na América Latina têm sido acompanhadas por uma nova forma de intervenção estético-política. O que poderíamos chamar de intervenções audiovisuais no espaço público.

Com a intenção de começar a traçar uma rota histórica através de diversas experiências que utilizaram a intervenção audiovisual como ferramenta de ataque simbólico em diversas arquiteturas hegemônicas. Neste texto, analisaremos a experiência do artista polonês Krzysztof Wodiczko, que com suas projeções públicas constitui uma das principais referências desta nova linguagem leve-projetiva.

Este trabalho explora brevemente seus postulados estéticos ao fazer suas projeções públicas sobre diferentes arquiteturas e monumentos públicos e corporativos, bem como seu interesse principal em se distanciar da noção de arte pública e a tentativa de questionar a noção de público e privado em cada uma de suas ações.

Também nos aprofundamos na passagem do artista polonês pela América Latina nos últimos anos e como podemos pensar nisso como um germe das ações projetivas desobedientes que agora iluminam nossos territórios.

Palavras chave: Intervenção Audiovisual - Triagem Pública - Krzysztof Wodiczko - Arte Pública.

[Las traducciones de los abstracts fueron supervisadas por el autor de cada artículo] 